\title{
Predictors of schizophrenia
}

\author{
Evidence from the Northern Finland 1966 Birth Cohort \\ and other sources*
}

MATTI ISOHANNI, ERIKA LAURONEN, KRISTIINA MOILANEN,
IRENE ISOHANNI, LIISA KEMPPAINEN, HANNU KOPONEN,
JOUKO MIETTUNEN, PIRJO MÄKI, SAMI RÄSÄNEN, JUHA VEIJOLA,
PEKKA TIENARI, KARL-ERIK WAHLBERG and GRAHAM K. MURRAY

\author{
Background Subtle motor, emotional, \\ cognitive and behavioural abnormalities \\ are often present in apparently healthy \\ individuals who later develop \\ schizophrenia, suggesting that some \\ aspects of causation are established \\ before overt psychosis.
}

\begin{abstract}
Aims To outline the development of schizophrenia.
\end{abstract}

\begin{abstract}
Method We drew on evidence from The Northern Finland 1966 Birth Cohort supplemented by selected findings from other relevant literature.
\end{abstract}

Results The main known risk factors in development of schizophrenia are genetic causes, pregnancy and delivery complications, slow neuromotor development, and deviant cognitive and academic performance. However, their effect size and predictive power are small.

Conclusions No powerful risk factor, premorbid sign or risk indicator has been identified that is useful for the prediction of schizophrenia in the general population.

\section{Declaration of interest The study was funded by special grants from the Finnish Academy, Sigrid Juselius Foundation, the Signe and Ane Gyllenberg Foundation, the Jalmari and Rauha Ahokas Foundation, and Stanley Medical Research Institute.}

\footnotetext{
* Paper presented at the Third International Early Psychosis Conference, Copenhagen, Denmark, September 2002.
}

Life span epidemiology is a novel way of approaching schizophrenia. There appear to be many developmental abnormalities in the premorbid phase that are distinct from the major psychotic symptomatology. These features present major challenges for theories of causation, as well as practical problems for the prediction of schizophrenia.

\section{METHOD}

We describe factors contributing to the development of schizophrenia. This is done by a selective review of literature concentrating on events during pregnancy, childhood and adolescence, and using The Northern Finland 1966 Birth Cohort as an entry point to the risk factors. The cohort is an unselected, general population sample assessed during mid pregnancy. It is based on 12068 pregnant women living in the provinces of Oulu and Lapland who were due to deliver during 1966, and consists of 12058 live born individuals. Information on biological, social and environmental factors has been collected prospectively from the antenatal period to the end of 2004. By 2001 there were 111 cases of DSM-III-R schizophrenia (American Psychiatric Association, 1987) in the cohort (Isohanni et al, 2004a).

\section{Genetic factors}

Twin, adoption and family studies provide consistent evidence that genetic factors are crucial in the familial aggregation of schizophrenia (Kendler, 2000). The presumed neurodevelopmental processes leading to schizophrenia are at least partly determined by genetic factors.

The familial predisposition (liability) for schizophrenia is not only for the psychosis but also for 'schizophrenia-like' personality disorders and probably for some non-schizophrenic non-affective psychoses. Molecular geneticists should search for susceptibility gene(s) for schizophrenia spectrum, rather than genes for manifest disorder. Unfortunately, from linkage and association studies (Tienari et al, 2003) we are uncertain what the correct phenotypic boundaries are for schizophrenia. No linkage appears to be consistently replicable even across large studies. Thus, it has to be questioned whether the genetic contribution is detectable by these strategies as it may be epigenetic (i.e. related to gene expression rather than to sequence variation) (DeLisi et al, 2002).

The pattern of inheritance is complex. It is likely that multiple genes and multiple environmental factors interact. However, heredity is not a fate but, instead, a kind of probability. Concordance between monozygotic twins is approximately $30-40 \%$ as compared with $10-15 \%$ in dizygotic twins (slightly higher if probandwise concordance has been used as compared with pairwise concordance). The clinical picture encountered in monozygotic co-twins without schizophrenia is variable, ranging from a duplication of the schizophrenic psychosis to schizotypal and paranoid personality disorder to neurotic symptoms and even clinical normality. The offspring of two parents with schizophrenia are non-schizophrenic in $60-70 \%$ of cases despite their extreme genetic and environmental risks (Kringlen, 2000). These results emphasise the importance of non-genetic factors.

Genotype-environment interaction can be defined as a genetic control of sensitivity to environmental factors, or environmental control of gene expression. The results from the Finnish adoption study support this hypothesis (Tienari et al, 2004). Thus, some genotypes are more likely to develop psychosis in the event of exposure to certain environmental factors. In the case of genotype-environment interaction, psychoses will tend to cluster in families not because of direct genetic effects, but because relatives are more vulnerable to the risk-increasing effect of prevalent environmental risk factors (van Os \& Marcekis, 1998). Wahlberg et al (1997, 2000) have shown that adoptees at risk for schizophrenia have more formal thought disorder than adoptees without such risk, if their adoptive parents have elevated communication deviance. The direction of effect is unclear, but it may be that both children and parents interact in a reciprocal, circular process. 


\section{Adverse events during pregnancy and delivery}

The association between obstetric complications and schizophrenia has provided crucial support for developmental and aetiological models of the disorder. Cannon et al $(2002 a)$ reviewed the literature on obstetric complications as risk factors for schizophrenia. They found that three groups of complications were significantly associated with schizophrenia. First, complications of pregnancy, including bleeding, pre-eclampsia, diabetes and rhesus incompatibility. The second category was abnormal foetal growth and development, low birth weight, congenital malformations and reduced head circumference. The third was complications of delivery: uterine atony, asphyxia and emergency Caesarean section. However, Cannon et al (2002a) found that pooled estimates of effect sizes were generally small. In the Northern Finland Birth Cohort, a more stringent definition of severe delivery complications resulted in a larger effect: schizophrenia was seven times as common in those exposed to an operationally defined measure of perinatal brain damage as in unexposed individuals (Jones et al, 1998).

\section{Central nervous system infections}

A variety of studies have reported that exposure to bacterial and viral infections (e.g. influenza) during the prenatal period increases the risk of subsequent schizophrenia in the offspring (Brown et al, 2004), although several studies have not confirmed this association (Suvisaari et al, 2003; Koponen et al, 2004). Preliminary evidence also suggests that cerebral infections in childhood may be risk factors for later schizophrenia: in the Finland Cohort (Rantakallio et al, 1997; Koponen et al, 2003) the adjusted odds ratio for schizophrenia after a viral central nervous system (CNS) infection was 4.8 (95\% CI 1.6$14.0)$, and the population attributable fraction was $4 \%$ (95\% CI 1.9-4.8). The clinical course of schizophrenia did not differ in those with or without CNS viral infection. There are several hypotheses on causality. Viral infection may disrupt cellular and molecular functioning and may also act by mimicking CNS neurotransmitters and receptors. Schizophrenia could also be caused by a latent, periodically reactivated virus, or by retroviral genomic material integrated into host cell DNA. Finally, it may be the immune response, rather than the infection itself that causes psychosis.

\section{Early neuromotor development}

Measures of premorbid function prior to the clinical manifestation of schizophrenia have revealed neuromotor abnormalities and developmental delays. Jones et al (1994) studied the British 1946 birth cohort and found evidence of delayed motor and speech development by the age of 2 years in children with premorbid symptoms. In the Northern Finland Birth Cohort the ages at learning to stand, walk and become potty trained were related to subsequent risk for schizophrenia and other psychoses: earlier milestones reduced, and later milestones increased the risk (Isohanni et al, 2001). Furthermore, in an extension of these findings, Isohanni et al (2004a) linked infant motor development and adolescent school performance in motor domains; they found that developmental continuity across these two differing measures of motor function was stronger in individuals with premorbid symptoms in comparison with general population controls.

\section{Early familial environment}

Schizophrenia has been seen to stem from childhood psychological and behavioural markers. Many possible psychosocial predisposing factors have been suggested, such as disturbances in parent-child relationships in the British 1946 birth cohort (Jones et al, 1994), communication deviance in the family (Goldstein, 1987) and several social factors. These findings suggest that aspects of the early familial environment can have an adverse impact on later mental health. The role of non-genetic familial factors is not clear.

In the Finland Cohort unwanted pregnancy was a risk factor for developing schizophrenia (Myhrman et al, 1996) and may operate directly or be a marker of other risk factors. First-born sons had an elevated risk for schizophrenia in the same cohort (Kemppainen et al, 2001). However, some factors have been found that are not associated with risk of schizophrenia: living in a single-parent family (Mäkikyrö et al, 1998), size of the family of origin (Kemppainen et al, 2000), antenatal depression in the mother (Mäki et al, 2004) or early separation (Mäki et al, 2003).

\section{Premorbid cannabis use}

Use of cannabis is about twice as common among psychotic patients as among controls in the general population. In 50000 Swedish army conscripts, cannabis use was associated with an increased risk of schizophrenia in a dose-dependent fashion (adjusted odds ratio for linear trend 1.2, 95\% CI 1.1-1.4) (Zammit et al, 2002). Two other recent cohort studies have replicated the association using psychotic symptoms as an outcome (Murray, R. M. et al, 2003). The risk for schizophrenia is higher among individuals with genetic vulnerability and those having some baseline psychiatric symptoms. Increased mesolimbic dopamine levels may be responsible for positive psychotic symptoms and one biologically plausible theory for causality is that cannabis increases the release of dopamine in the mesolimbic pathway.

\section{Premorbid cognitive and scholastic performance}

Patients with schizophrenia, as a group, have global intellectual impairments. Some of these impairments pre-date the onset of psychotic symptoms. Population-based studies from birth cohorts and army conscripts have demonstrated that, when considered as a group, individuals who later develop schizophrenia show lower premorbid IQ than the general population. The lower the IQ, the higher the risk of developing schizophrenia later (Jones et al, 1994; Davidson et al, 1999; Zammit et al, 2004). Interestingly, this finding of premorbid IQ deficits seems to differentiate schizophrenia from bipolar disorder. For example, in a New Zealand birth cohort sample, Cannon et al (2002b) found mild deficits in premorbid IQ (and motor function) measured in early and middle childhood in individuals who went on to suffer from schizophreniform disorder, whereas those who went on to suffer mania performed at the same level as controls.

Poor school performance has been presented as a premorbid sign since Bleuler. A number of other school-related risk factors for developing schizophrenia have been identified: repeating a grade, difficulties in completing the final level of schooling, and social and behavioural problems (Isohanni et al, 1998). Thus it might be expected that individuals in the premorbid phase would perform poorly at school in comparison with their classmates. However, results from population-based studies have not provided clear support for this. In the Finland cohort adolescents who were below their expected normal grade were 
three times more likely to develop schizophrenia than those in their normal grade. However, low school marks did not predict schizophrenia - not even in areas requiring skilled motor performance, such as sports and handicrafts (Isohanni et al, 1998). In another Finnish sample, individuals with premorbid symptoms performed below controls in non-academic skills (sports and handicrafts), although with respect to academic and behavioural factors there were no significant differences (Cannon $e t$ al, 1999).

The identification of these risk factors has raised hopes of predicting later psychosis in healthy children and adolescents, and some groups have developed algorithms with claims of impressive predictive power (Olin et al, 1998; Davidson et al, 1999). However, the positive predictive value of a test is dependent on the prevalence of the disorder in question; for rare disorders, such as schizophrenia, trying to distinguish early instances of premorbid symptoms from the general population is difficult (Murray, G. K. et al, 2003).

A few methodologically limited or nonreplicated studies show that creativity may be a risk factor for developing schizophrenia (reviewed by Waddell, 1998). A surprising and non-replicated finding from the Northern Finland 1966 Birth Cohort was that $11 \%$ of boys with premorbid symptoms had excellent school marks (on average) compared with $3 \%$ in the healthy population (odds ratio $=3.8 ; 95 \%$ CI 1.6-9.3) (Isohanni et al, 1999). When investigating the entire population of Iceland, Karlsson (2004) found an exceptionally high level of academic performance, especially in mathematics, among individuals with psychosis and their healthy relatives. This association, if true, is theoretically interesting and relevant both to preservation of schizophrenia in the population, and to mechanisms of developing schizophrenia. Deviation from the norm in either direction warrants further study as a risk factor for schizophrenia.

\section{Gender differences on early predictors}

The later age of onset of schizophrenia in women has been widely reported (reviewed by Räsänen et al, 2000). However, there is evidence that there are no differences between men and women in the earliest symptoms and signs during the prodromal phase (Häfner, 2003). Earlier, in the premorbid phase, social functioning of men is poorer (Foerster et al, 1991). In this phase, girls may have more introspective symptoms, such as shyness and flat expression of emotion, and boys more behavioural problems and conflicts (Done et al, 1994). Neurological soft signs have been found to be raised in the premorbid phase (Jones et al, 1994), more commonly in boys (Walker \& Levine, 1990). It has been argued that more men than women with schizophrenia have a form of disease due to a neurodevelopmental anomaly (Castle et al, 1996).

\section{RESULTS}

An increasing trend in medicine is to link basic neurobiology, epidemiology and clinical research into biopsychosocial models, as well as to formulate longitudinal pathways from asymptomatic, subthreshold and threshold stages to clinical disease over the life span. This kind of integrative approach is increasingly used when the causal mechanisms of some new or reinvented potential risk factors (e.g. seasonality of birth, migration, urban birth, ethnicity) are analysed.

Utilising the Northern Finland 1966 Birth Cohort, we have tried to formulate a comprehensive model of the known theoretical background, aetiological components and life-span course of schizophrenia (Isohanni et al, 2000, 2004b). Further details of these descriptive models of schizophrenia (as well as the results) are presented as parts of doctoral theses that are freely available to all on the internet (Isohanni, 2000; Kemppainen, 2001; Riala, 2004).

\section{DISCUSSION}

No convincing risk factors have been identified for predicting the onset of schizophrenia in the general population. However, the immediate prospects are potentially better in ultra-high-risk clinic samples who may already be experiencing features of the prodromal phase (McGorry et al, 2002). These clinics are often active research facilities which also aim to improve clinical practice. Other advances come from selected series that show strong genetic liability or are 'ultra-high-risk' groups. In clinical decision-making in the prodrome or imminent psychosis, individuals should be assessed with careful interviews; historical data may be used as one element of the decision-making algorithm.

\section{REFERENCES}

American Psychiatric Association (1987) Diagnostic and Statistical Manual of Mental Disorders (3rd edition, revised) (DSM-III-R). Washington, DC: APA

Brown, A. S., Begg, M. D., Gravenstein, S., et al (2004) Serologic evidence of prenatal influenza in the etiology of schizophrenia. Archives of General Psychiatry, 61, 774-80.

Cannon, M., Jones, P. B., Huttunen, M. O., et al (1999) School performance in Finnish children and later development of schizophrenia. A population-based longitudinal study. Archives of General Psychiatry, 56, 457-463.

Cannon, M., Jones, P., Murray, R. (2002a) Obstetric complications and schizophrenia: historical and metaanalytical review. American Journal of Psychiatry, I59, 1080-1092.

Cannon, M., Caspi, A., Moffitt, T. E., et al (2002b)

Evidence for early-childhood, pan-developmental impairment specific to schizophreniform disorder: results from a longitudinal birth cohort. Archives of General Psychiatry, 59, 449-456.

Castle, D. J., Sham, P. J., Wessely, S., et al (1996) The sub-typing of schizophrenia in men and women: a latent class analysis. Psychological Medicine, 24, 4I-5I.

Davidson, M., Reichenberg, A., Rabinowitz, J., et al (1999) Behavioural and intellectual markers for schizophrenia in apparently healthy male adolescents. American Journal of Psychiatry, 156, 1328-1335.

DeLisi, L. E., Shaw, S. H., Crow, T. J., et al (2002) A genome-wide scan for linkage to chromosomal regions in 382 sibling pairs with schizophrenia or schizoaffective disorder. American Journal of Psychiatry, 159, 803-812.

Done, D. J., Crow, T. J., Johnstone, E. C., et al (1994) Childhood antecedents of schizophrenia and affective illness: social adjustment at ages 7 and II. BMJ, 309, 699-703.

Foerster, A., Lewis, S., Owen, M., et al (1991) Premorbid adjustment and personality in psychosis. Effects of sex and diagnosis. British Journal of Psychiatry, 158, $17 \mid-176$

Goldstein, M. J. (1987) Family interaction patterns that antedate the onset of schizophrenia and related disorders: a further analysis of data from a longitudinal, prospective study. In Understanding Major Mental Disorder: The Contribution of Family Interaction Research (eds H. Hahlweg \& M. J. Goldstein), pp. II-32. New York: Family Process Press.

Häfner, H. (2003) Prodrome, onset and early course of schizophrenia. In The Epidemiology of Schizophrenia (eds B. Murray, P. Jones, E. Susser, et al), pp. 124-147. Cambridge, UK: Cambridge University Press.

Isohanni, I. (2000) Education and Mental Disorders. A 31-year Follow-Up in the Northern Finland 1966 Birth Cohort, p. 80. Retrieved from http: / / herkules.oulu.fi/ isbn9514258398/

Isohanni, I., Järvelin, M.-R., Nieminen, P., et al (1998) School performance as a predictor of psychiatric hospitalization in adult life. A 28 -year follow-up in the Finnish 1966 Birth Cohort. Psychological Medicine, 28, 967-974.

Isohanni, I., Järvelin, M.-R., Jones, P., et al (1999) Can excellent school performance be a precursor of schizophrenia? A 28-year follow-up in the Northern 
Finland 1966 Birth Cohort. Acta Psychiatrica

Scandinavica, 100, 17-26.

Isohanni, M., Jones, P., Kemppainen, L., et al (2000) Childhood and adolescent predictors of schizophrenia in the Northern Finland 1966 Birth Cohort - a descriptive life-span model. European Archives of Psychiatry and Clinical Neuroscience, 250, 311-319.

Isohanni, M., Jones, P., Moilanen, K., et al (200I) Early developmental milestones in adult schizophrenia and other psychoses. A 31-year follow-up of the North Finland 1966 Birth Cohort. Schizophrenia Research, 52, $1-19$.

Isohanni, M., Murray, G. K., Jokelainen, J., et al (2004a) The persistence of developmental markers in childhood and adolescence and risk of schizophrenic psychoses in adult life. A 34-year follow-up of the North Finland 1966 Birth Cohort. Schizophrenia Research, 7I, 213-225.

Isohanni, M., Isohanni, I., Koponen, H., et al (2004b)

Developmental precursors of psychosis. Current Psychiatry Reports, 6, 168-175.

Jones, P., Rodgers, B., Murray, R., et al (1994) Child developmental risk factors for adult schizophrenia in the British 1946 birth cohort. Lancet, 344, 1398-1402.

Jones, P., Rantakallio, P., Hartikainen, A.-L., et al (1998) Schizophrenia as long-term outcome of pregnancy, delivery and perinatal complications: a 28-year follow-up of the 1966 North Finland general population birth cohort. American Journal of Psychiatry, I55, 355-364.

Karlsson, J. L. (2004) Psychosis and academic performance. British Journal of Psychiatry, 184, 327-329.

Kemppainen, L. (200I) Family Predictors of Severe Mental Disorders and Criminality in the Northern Finland

1966 Birth Cohort. Retrieved from http: / herkules.oulu.fi/oulu.fi/isbn9514258398/

Kemppainen, L., Mäkikyrö, T., Jokelainen, J., et al (2000) Is grand multiparity associated with offspring's hospital-treated mental disorders? A 28-year follow-up of the Northern Finland 1966 Birth Cohort. Social Psychiatry and Psychiatric Epidemiology, 35, 104-108.

Kemppainen, L., Veijola, J., Jokelainen, J., et al (200I) Birth order and risk for schizophrenia: a 31-year followup of the Northern Finland 1966 Birth Cohort. Acto Psychiatrica Scandinavica, 104, 148-152.

Kendler, K. S. (2000) Schizophrenia: genetics. In Comprehensive Textbook of Psychiatry (eds B. Sadock \& V. Sadock), pp. I147-1158. New York: Lippincott.

Koponen, H., Rantakallio, P., Veijola, J., et al (2004) Childhood central nervous system infections and risk for schizophrenia. European Archives of Psychiatry and Clinical Neuroscience, 254, 9-13.

Kringlen, E. (2000) Twin studies in schizophrenia with special emphasis on concordance figures. American Journal of Medical Genetics, 97, 4-II.

Mäki, P., Veijola, J., Joukamaa, M., et al (2003) Maternal separation at birth and schizophrenia - a long term follow-up of the Finnish Christmas Seal Home Children. Schizophrenia Research, 60, 13-19.

\section{Mäki, P., Veijola, J., Rantakallio, P., et al (2004)}

Schizophrenia in the offspring of antenatally depressed mothers - a 31 year follow-up of the Northern Finland 1966 Birth Cohort (letter). Schizophrenia Research, 66, $79-81$.

Mäkikyrö, T., Sauvola, A., Moring, J., et al (1998) Hospital-treated psychiatric disorders in adults with a single-parent and two-parent family background: a 28-year follow-up of the 1966 Northern Finland Birth Cohort. Family Process, 37, 335-344.

\section{CLINICAL IMPLICATIONS}

- No powerful factor has been identified that is useful for the prediction of schizophrenia in the general population.

- In clinical high-risk samples predictive power may be better.

- Careful assessment of premorbid risk factors combined with follow-up of an individual and family may help in clinical decision-making.

\section{LIMITATIONS}

- Much of the evidence presented here comes from one sample, the Northern Finland 1966 Birth Cohort.

- The results of the Northern Finland 1966 Birth Cohort are only generalisable to cases of onset before 35 years of age.

- Studying life-span epidemiology of schizophrenia in a prospective birth cohort setting avoids selection bias but is laborious and may lack statistical power.

MATTI ISOHANNI, MD, PhD, ERIKA LAURONEN, MD, KRISTIINA MOILANEN, MD, IRENE ISOHANNI, PhD, LIISA KEMPPAINEN, MD, PhD, HANNU KOPONEN, MD, PhD, JOUKO MIETTUNEN, PhD, PIRJO MÄKI, MD, PhD, SAMI RÄSÄNEN, MD, PhD, JUHA VEIJOLA, MD, PhD, PEKKA TIENARI, MD, PhD, KARL-ERIK WAHLBERG, PhD, Department of Psychiatry, University of Oulu, Finland; GRAHAM K. MURRAY, MRCPsych, Department of Psychiatry, University of Cambridge, UK

Correspondence: Dr Matti Isohannni, Department of Psychiatry, University of Oulu, PO Box 5000, Finland. E-mail: matti.isohanni@oulu.fi

Murray, G. K., Isohanni, M., Isohanni, l., et al (2003) School and schizophrenia. In Preventive Strategies for Schizophrenic Disorders (ed. A. Grispini), pp. 244-268 Rome: Giovanni Fioriti.

Murray, R. M., Grech, A., Phillips, P., et al (2003) What is the relationship between substance abuse and schizophrenia? In The Epidemiology of Schizophrenia (eds R. M. Murray, P. B. Jones, E. Susser, et al), pp. 317-342. Cambridge, UK: Cambridge University Press.

Myhrman, A., Rantakallio, P., Isohanni, M., et al (1996) Unwantedness of a pregnancy and schizophrenia in the child. British Journal of Psychiatry, 169, 637-640.

Olin, S.-C., Mednick, S. A., Cannon, T., et al (1998) School teacher ratings predictive of psychiatric outcome 25 years later. British Journal of Psychiatry, 172 (suppl. 33), $7-13$

Rantakallio, P., Jones, P., Moring, J., et al (1997) Association between central nervous system infections during childhood and adult onset schizophrenia and other psychoses: a 28-year follow-up. International journal of Epidemiology, 26, 837-843.

Räsänen, S., Pakaslahti, A., Syvälahti, E., et al (2000) Gender differences in schizophrenia. A review. Nordic Journal of Psychiatry, 54, 37-45.

Riala, K. (2004) Adolescent Predictors of Adult Social and Psychiatric Adversities. A Prospective Follow-Up Study of the Northern Finland 1966 Birth Cohort. Retrieved from http: //herkules.oulu.fi/isbn9514274954/

Suvisaari, J., Mautemps, N., Haukka, J., et al (2003) Childhood and central nervous system viral infection and adult schizophrenia. American Journal of Psychiatry, 160, $1183-1185$.
Tienari, P., Wynne, L. C., Läksy, K., et al (2003) Genetic boundaries of the schizophrenia spectrum: evidence from the Finnish Adoptive Family Study. American Journal of Psychiatry, 160, I587-1594.

Tienari, P., Wynne, L. C., Sorri, A., et al (2004) Genotype-environment interaction in schizophrenia spectrum disorder: long-term follow-up study of Finnish adoptees. British Journal of Psychiatry, 184, 216-222.

van Os, J. \& Marcekis, M. (1998) The ecogenetics of schizophrenia. Schizophrenia Research, 32, 127-135.

Waddell, C. (1998) Creativity and mental illness: is there a link? Canadian Journal of Psychiatry, 43, 166-173.

Wahlberg, K.-E., Wynne, L. C., Oja, H., et al (1997) Gene-environment interaction in vulnerability to schizophrenia: findings from the Finnish Adoptive Family Study. American Journal of Psychiatry, 154, 355-362.

Wahlberg, K.-E., Wynne, L. C., Oja, H., et al (2000) Thought disorder index of Finnish adoptees and communication deviance of their adoptive parents. Psychological Medicine, 30, 127-136.

Walker, E. \& Lewine, R. J. (1990) Prediction of adultonset schizophrenia from childhood home movies of the patients. American Journal of Psychiatry, 147, 1052-1056.

Zammit, S., Allebeck, P., Andréasson, S., et al (2002) Self-reported cannabis use as a risk factor for schizophrenia in Swedish conscripts of 1969: historical cohort study. BMI, 325, 1199

Zammit, S., Allebeck, P., David, A. S., et al (2004) A longitudinal study of premorbid IQ score and risk of developing schizophrenia, bipolar disorder, severe depression, and other nonaffective psychoses. Archives of General Psychiatry, 61, 354-360. 